\title{
MEDA and its use in data collecting and evaluating
}

\author{
Vladimír Plos \\ Department of Air Transport \\ CTU in Prague, Faculty of Transportation Sciences \\ Prague, Czech Republic \\ plosvlad@fd.cvut.cz
}

\begin{abstract}
Article discusses the use of the Maintenance error decision aid (MEDA) methodology in the investigation of events and subsequent data collection and assessment which is needed for the collection and evaluation of safety indicators. The first part describes the methodology of MEDA, the second outlines the use of factors for the purposes of collecting safety indicators and evaluation of the safety performance of the organization in terms of implementation of risk factors contributing to the realization of unwanted events.
\end{abstract}

Keywords-MEDA; safety; indicator; risk; event investigation;

\section{INTRODUCTION}

Safety evaluation in terms of safety performance is recently more and more popular. At first it was a unique attempt by operators to find and learn from the mistakes that occur during normal activities in everyday processes. This effort is now transformed into legislative requirements. So nowadays there is currently ongoing effort by all operators in air transport on the introduction of safety indicators to show the performance of "safety department". To find suitable indicators for the various areas of air transport is a task with varying levels of difficulty. One of the developed tools is Boeing's Maintenance methodology error of decision aid (MEDA). This methodology deals with the progress in the investigation of event incurred in the maintenance of aircraft and aims to identify the causes of such events. Besides its own investigatory process, this model is extended by an investigation to identify the factors affecting events, feedback, taking corrective actions, etc. Methodology MEDA provides a detailed description of the groups of factors influencing the realization of the event.

\section{MEDA METHODOLOGY AND ITS USAGE}

If we want to collect and analyse safety data on the occurrence of unwanted events in our organization, it is necessary to answer the question, what and how we gather the safety data. In some sectors of aviation there are relatively strict requirements for which events should be reported to civil aviation authority, in what format, what content data, etc. However, aircraft maintenance organisations do not have many events that are subject to the reporting system. For those organizations that also want to monitor and assess their safety level, it is therefore important to establish a workable set of criteria, which can be efficiently collect and evaluate. For use in maintenance organizations appear appropriate methodology developed by Boeing for the investigation of events in the maintenance. MEDA methodology provides investigators a detailed description of activities that can be done not only to find the culprit of event, but also to make it possible to identify all the causes of the event, i.e. the factors that contributed to the realization of the event. In most cases, this is not just a failure of an individual, but as is known from the theory of safety, there is an accumulation of factors which themselves may not be sufficient to the event realisation, but if they are gathered at the same time it is possible to realize the unwanted events. The standard model of events investigation (Fig. 1) shows the established approach to the investigation, where the priority is to find a responsible person who caused the incident. This model, despite a general knowledge of its outdated is still in use in some organizations, and thanks to this fact the "intimidation" of staff and thereby build the climate of unwillingness to report anything because of possible punishment.

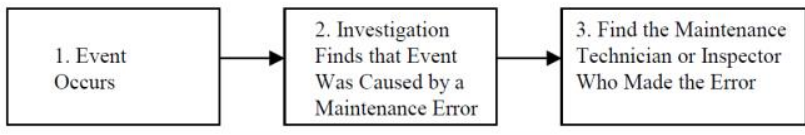

Figure 1. Standard investigation chain [1]

In contrast, Fig. 2 shows a model of the correct approach to event investigation, when the investigator is not satisfy with finding the culprit who caused the event, but goes more in depth and try to investigate some influential factors in the incident, which all led to its realization. This is actually the principles of Safety Management System when it is necessary to find the true cause(s) of the problem and focus on those corrective actions. Only this way will be an investigation effective with closed safety loop (hazard identification investigating the events Risk Assessment - evaluation of factors contributing to the event, risk management - hiring the right security measures). Approach in Figure 1 is based solely on finding the culprit and other safety management department activities are not affected.

The model in Figure 2 is an extension of the first one and consists of interview with the responsible person for the fact that an event occurs. Then there are some analytical steps and finally, the adoption of safety measures, together with feedback towards the staff. Thanks to the interviews factors that contributed to the event are identified. Factors can be divided into eight basic groups. This is an informative character factors, 
factors associated with tools, knowledge, environment, communications, etc. - A total of 10 major categories. These categories are further divided into more detailed categories, as shown below in Figure 3.

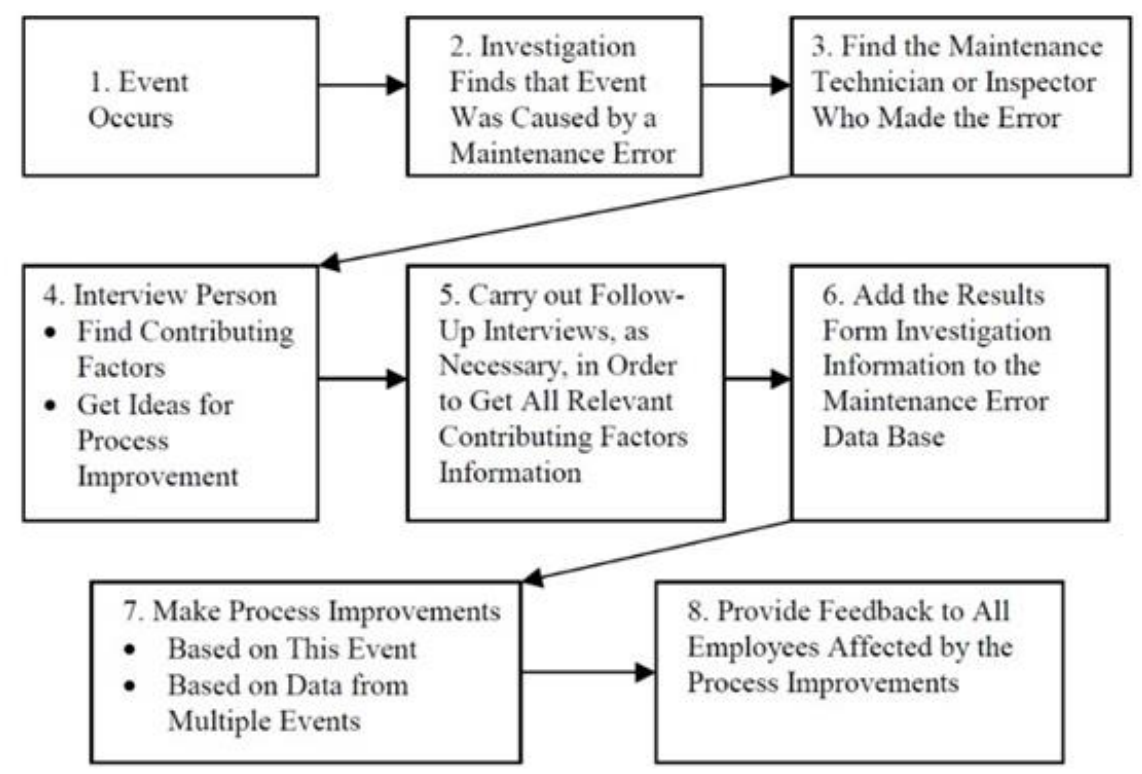

Figure 2. Improved investigation chain [1]

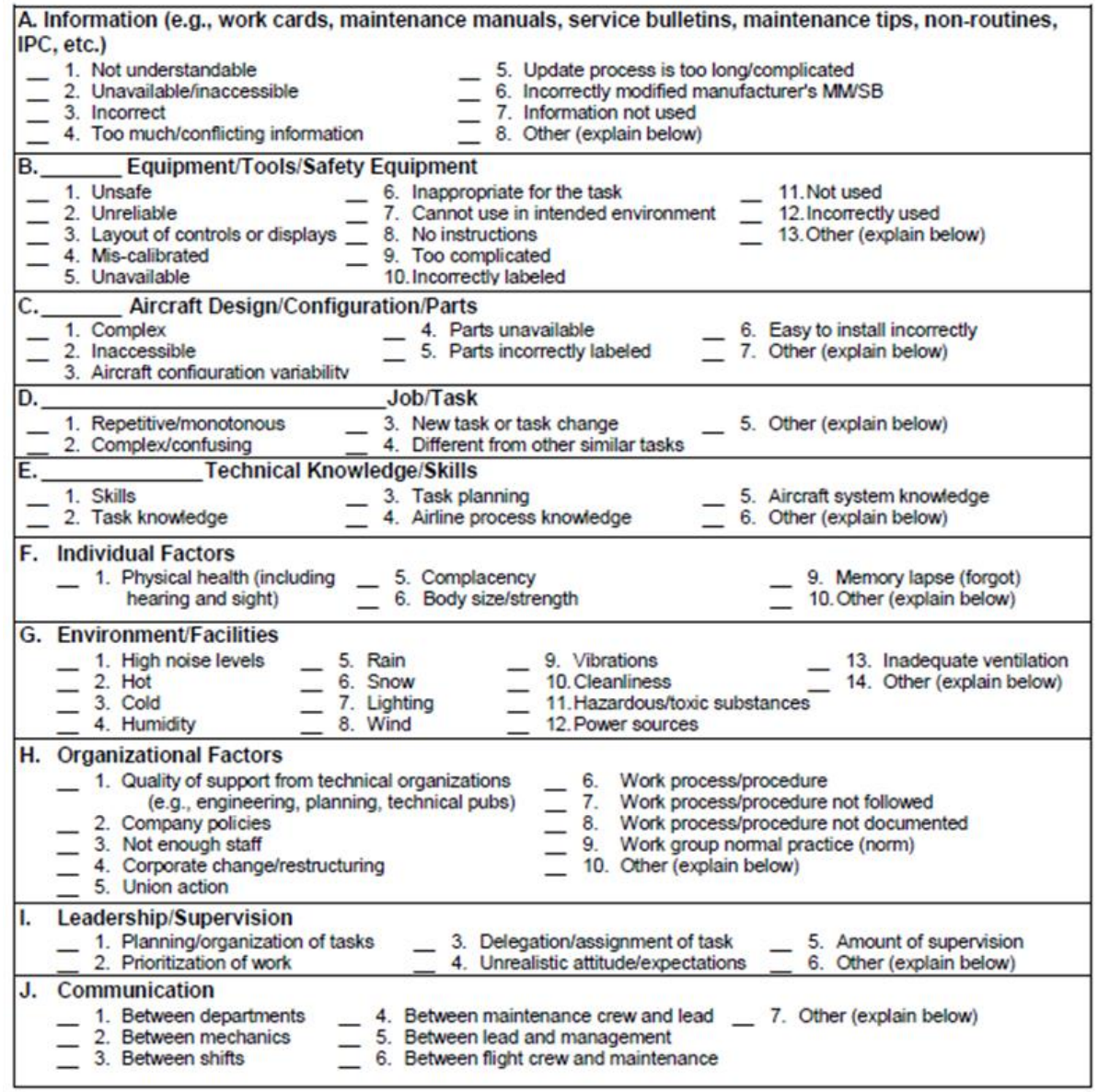


Based on the identified factors can be taken effective safety measures that will not only focus on one person, but will cover the work in a wider context and should include improving the operating environment, streamlining processes for all workers on the jobsite.

III. USING THE MEDA METHODOLOGY AS AN INSTRUMENT FOR COLLECTING AND EVALUATING SAFETY INDICATORS IN THE AIRCRAFT MAINTENANCE

Using the procedure described above using investigation methodology MEDA it is evident that the collection of particular events factors, we have a statistical summary of the number of each factor occurrences. From a statistical summary it is possible with certain adjustments to take the form of safety indicators. The first prerequisite is to relate the number of the case to a measurable unit, for example a number of events based on the number of operations, the number of different types of maintenance performed in a given period, etc. Based on these values and their characteristics we can monitor trends and possibly through targeted safety measures adopted on trouble spots in processes we can manage and increase the level of safety in the organization. If we use the principle of MEDA methodology, we can use some groups of different factors as safety indicators of maintenance organization. Some of them can of course be further divided, but it will depend on the organization, their procedural problems, what are the characteristics of normal operations etc.

Factors that are in the basic characterization of the methodology are intended mainly for the events that have the nature of a failure in the work environment - incorrect assembly element, damage etc. But these events are occurring in the environment maintenance organization with small repetition frequency. In a far greater extent it is the audit findings. It is necessary to expand the existing group of factors on some specific terms affecting areas which are not monitored in the methodology MEDA.

\section{INDICATORS EVALUATING}

Based on indicators collection, we receive the value of the frequency of individual items in time with respect to the characteristics of the operations, types of maintenance, etc. For proper operation and adherence to the principle of safety indicators is needed to set boundaries, boundaries that will be limiting safety space. Determining such limits are based on an assessment of whether it is sustainable status quo - it can be the upper limit of the state from the previous period. Using the formula below (1), it is possible to determine the space for warnings before overcoming boundaries.

$$
\sigma=\sqrt{\frac{\sum(x-\mu)^{2}}{N}}
$$

In the formula, $\mathrm{N}$ represents the number of data samples, $\mathrm{X}$ value of the indicator in the period and " $u$ " the average value of the indicator for the whole period. Graphic explanation of the formula components is in the following figure - for example, if we wanted to assess the annual indicators development.

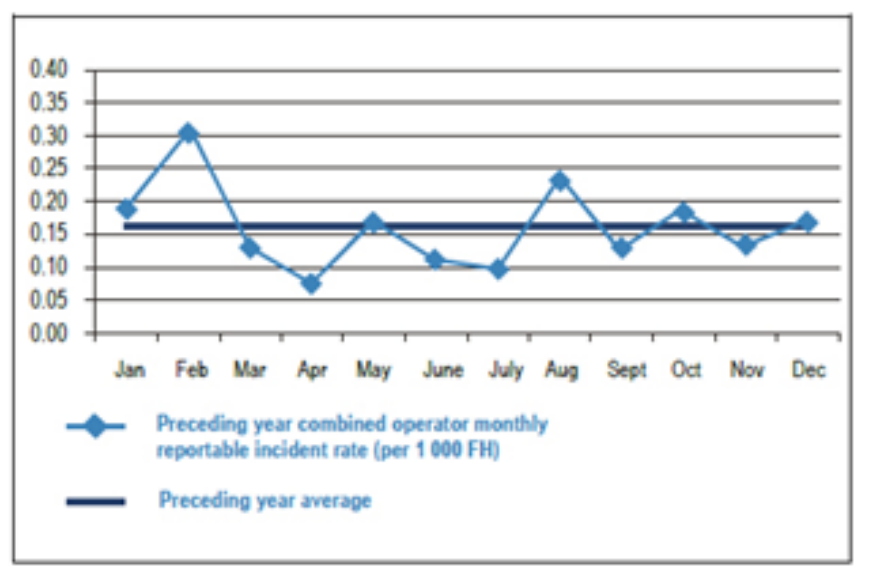

Figure 4. Progress of indicator monthly values [2]

Thus obtained indicators and limit values may already be used by safety manager of organization and on their basis take safety precautions especially if limits are exceeded.

If we go more in depth and various indicators will be linked with the realization of senior events, we discover their contribution to the realization - their seriousness. By this, now it is in the row of risk-based indicators. Risk indicators improve the simple monitoring of values and taking action when dealing with individual indicators from the perspective of their possible contribution to the realization of top events.

\section{CONCLUSION}

The issue of safety indicators concerns the whole aviation not only the flights themselves, but also areas such as processes in maintenance organizations. Data collection and evaluation is a precondition for the successful solution of the issue of safety indicators. For the successful collection and evaluation is needed to determine what data is appropriate for us. The solution of this problem in maintenance organisations may be the use of MEDA methodology, the use of factors that this methodology includes these groups further expand the factors that have been identified based on the analysis of events that occur in our organization.

\section{ACKNOWLEDGMENT}

This paper was supported by the Grant Agency of the Czech Technical University in Prague, grant No. SGS14/167/OHK2/2T/16.

\section{REFERENCES}

[1] BOEING. Maintenance Error Decision Aid: Users Guide. 1995.

[2] ICAO Doc 9859 Safety Management Manual. ISBN: 978-92-9249-2144. 3.vydání. Montréal, Quebec, Kanada: International Civil Aviation Organization, 2013 
[3] ØIEN, K., I.B. UTNE a I.A. HERRERA. Building Safety indicators: Part 1 - Theoretical foundation. Safety Science. 2011, vol. 49, issue 2, p. 148-161. DOI: 10.1016/j.ssci.2010.05.012. available at: http://linkinghub.elsevier.com/retrieve/pii/S0925753510001335.

[4] ØIEN, K., I.B. UTNE, R.K. TINMANNSVIK a S. MASSAIU. Building Safety indicators: Part 2 - Application, practices and results. Safety Science. 2011, vol. 49, issue 2, s.
[5] Mikan, A. - Vittek, P.: Creating Safety in Current Civil Aviation. In New Trends in Civil Aviation 2011. Praha: ČVUT v Praze a OSL ČR, 2011, p. 89-91. ISBN 978-80-01-04893-1.

[6] Mikan, A. - Vittek, P.: Measuring Safety Level Before Incident or Accident in Current Civil Aviation. In InAir 2012. Žilina: EDIS, 2012, p. 94-97. ISBN 978-80-554-0574-2.

[7] Technical Writer's Handbook. Mill Valley, CA: University Science, 1989. 